\title{
Overexpression of neogenin inhibits cell proliferation and induces apoptosis in human MDA-MB-231 breast carcinoma cells
}

\author{
QINGSONG ZHANG $^{1 *}$, FANG LIANG $^{2 *}$, YANG KE $^{2}$, YANPING HUO $^{1}$, \\ MINGCHUANG LI ${ }^{1}$, YANYAN $\mathrm{LI}^{2}$ and JUNMIN YUE ${ }^{3}$ \\ Departments of ${ }^{1}$ Breast Surgery, ${ }^{2}$ Oncology and ${ }^{3}$ Urology, Zhengzhou Central Hospital \\ Affiliated to Zhengzhou University, Zhengzhou, Henan 450007, P.R. China
}

Received December 15, 2014; Accepted February 13, 2015

DOI: $10.3892 /$ or.2015.4004

\begin{abstract}
Neogenin has been documented as playing an important role in cancer development. Although an elevated expression of neogenin has been detected in human breast cancer, the role of neogenin in breast cancer cells is not clearly understood. In the present study, we investigated neogenin in breast cancer cell proliferation, migration and apoptosis. We found that neogenin overexpression markedly reduced the proliferation and migration of breast cancer cells $(\mathrm{P}<0.05)$. Neogenin overexpression resulted in a reduction in the apoptosis rate. Inhibition of neogenin expression by neogenin siRNA dramatically promoted the proliferation and migration of breast cancer cells, whereas it inhibited cell apoptosis. Furthermore, we found that BMP-2-induced phosphorylation of Smad1/5/8 which was inhibited by neogenin overexpression. The present study demonstrates that neogenin may be a tumor suppressor in breast cancer. Neogenin may serve as a potential diagnostic marker and therapeutic target for breast cancer.
\end{abstract}

\section{Introduction}

Breast cancer is the most common malignant tumor in women, and the leading cause of cancer mortality in females that causes approximately half a million deaths each year worldwide $(1,2)$. Although recent substantial progress has been achieved in treatments involving chemotherapy, surgery and radiation therapy, breast cancer is still difficult to cure because of the propensity of these tumors to form distant metastases $(3,4)$ and the distinct subtypes that exist (5-7). Therefore, to cure breast

Correspondence to: Dr Junmin Yue, Department of Urology, Zhengzhou Central Hospital Affiliated to Zhengzhou University, 195 Tongbai Avenue, Zhengzhou, Henan 450007, P.R. China

E-mail: junminyues@163.com

${ }^{*}$ Contributed equally

Key words: breast cancer, neogenin, proliferation, migration, apoptosis cancer, we should understand the relevant molecular mechanisms involved in breast cancer metastasis. Evidence suggests that many characteristics and markers, such as the progesterone receptor, histological grade, HER2/ERBB2 status, the estrogen receptor, p53 mutational status and neogenin are able to classify heterogeneous breast cancers $(1,8)$. More recently, previous studies have indicated that neogenin expression may be inversely correlated to the tumorigenicity of human breast cancer (8); however, the specific function of neogenin in the progression of breast cancer is unclear.

Neogenin, a homologue of the DCC (deleted in colorectal cancer) receptor group, encodes a 1461 amino acid identity. Neogenin is widely distributed in the CNS and is a dependent receptor of the repulsive guidance molecule a (RGMa) (9-11). Previous studies have suggested that neogenin plays an important role in cell to cell recognition, tissue growth regulation, cellular differentiation, cell migration, cell apoptosis, angiogenesis, epithelial cell renewal and histogenesis (12-16). It has been reported that neogenin is expressed in many adult tissues, and abnormal expression of neogenin has been found in a variety of human cancers, such as pancreatic (17), colon cancer (18), esophageal squamous cell carcinoma (ESCC) (19), gliomas (20) and breast cancer (8). Subsequent studies revealed that altered expression of neogenin may lead to loss of proapoptotic activity and may even cause tumorigenesis (21). There is some evidence to suggest that downregulation of neogenin accelerates glioma progression through promoter methylation and its overexpression in SHG-44 induced apoptosis (20). Moreover, Lee and colleagues (8) reported that neogenin expression is downregulated in human breast cancer relative to the normal breast tissue.

A protein which can regulate cancer-relevant cellular functions such as cellular proliferation and apoptosis may be the potential source of molecular signaling pathways commonly disrupted in cancer cells $(22,23)$. Evidence suggests that bone morphogenetic proteins (BMPs) regulate many mammalian physiological and pathophysiological processes (24). BMPs bind to kinase receptors, thereby activating Smad transcription factors. Moreover, it has been reported that neogenin is a receptor for BMPs (24). Thus, we speculated that neogenin could modulate Smad signal transduction through binding with BMPs. In the present study, we demonstrated that neogenin overexpression can inhibit cell proliferation and 
migration; moreover, promoting cell apoptosis. The present study provides the first direct evidence in breast cancer cells that neogenin overexpression can result in cell growth inhibition and apoptosis.

\section{Materials and methods}

Antibodies. A rabbit monoclonal phospho-specific antibody to Smad1/5/8 was obtained from Cell Signaling Technology (Beverly, MA, USA). Rabbit anti-Smad1 monoclonal antibody, rabbit anti-neogenin monoclonal antibody, mouse anti- $\beta$-actin monoclonal antibody, HRP-conjugated rabbit anti-mouse IgG and HRP-conjugated goat anti-rabbit IgG were obtained from Abcam (Cambridge, MA, USA).

Cell culture and transfection. The human breast cancer cell lines MDA-MB-231, MCF-7 and T47D cells (all cell types from the American Type Culture Collection, Manassas, VA, USA) were cultured in Dulbecco's modified Eagle's medium (DMEM) supplemented with 10\% fetal bovine serum (FBS; Gibco-BRL, Gaithersburg, MD, USA), $1 \%$ penicillinstreptomycin and $1 \%$ glutamine. All the cells were grown and maintained at $37^{\circ} \mathrm{C}$ under a humidified atmosphere of $5 \% \mathrm{CO}_{2}$. MDA-MB-231 cells were transiently transfected in a 24-well plate with either human neogenin cDNA (pcDNA3.1-neogenin) or the control vector pcDNA3.1 using Lipofectamine 2000 reagent (Invitrogen, Carlsbad, CA, USA) according to the manufacturer's protocol. These cells were assayed 24, 48, 72 and $96 \mathrm{~h}$ after transfection.

MTT proliferation assay. Cell proliferation in MDA-MB-231, MCF-7 and T47D cells was detected using the MTT assay according to a method previously described (4). Briefly, transfected cells and control cells were plated in 96-well plates at $5 \times 10^{3}$ cells/well and cultured in DMEM for $48 \mathrm{~h}$. Next, the culture medium was replaced with $100 \mu \mathrm{l}$ of fresh DMEM, then $20 \mu \mathrm{l}$ MTT $(5 \mathrm{mg} / \mathrm{ml})$ was added to the cells for another $4 \mathrm{~h}$ at $37^{\circ} \mathrm{C}$. Formazan crystals were dissolved in $200 \mu \mathrm{l}$ of dimethyl sulfoxide (DMSO) and the absorbance was measured at $\lambda 595 \mathrm{~nm}$ with a spectrophotometer (Multiskan MK3; Thermo Fisher Scientific, Waltham, MA, USA).

Transwell migration assays. MDA-MB-231 cell migration was detected according to the method described in a previous study (16). Briefly, MDA-MB-231 cells were transfected with neogenin, and then the cells $\left(5 \times 10^{3}\right.$ cells/well $)$ were added to the upper Transwell (Corning Costar, Corning, NY, USA) chambers with $0.5 \mathrm{mg} / \mathrm{ml}$ collagen type I (BD Biosciences, Seoul, Korea) coated filters $24 \mathrm{~h}$ after transfection. DMEM containing $10 \%$ fetal bovine serum, $1 \%$ penicillin-streptomycin and $1 \%$ glutamine was added to the lower chamber and incubation was continued for $24 \mathrm{~h}$. Wide-field microscopy was used to quantify the cells that migrated to the lower chamber. Cells were counted at five randomly selected areas in each well.

Detection of apoptotic cells by flow cytometry. At $48 \mathrm{~h}$ after transfection, apoptosis of MDA-MB-231 cells was detected by flow cytometry. Subsequently, the cells were stained with Annexin V-FITC and propidium iodide (PI) for $20 \mathrm{~min}$ at room temperature. The apoptotic cells were then analyzed by flow cytometry (Beckman Coulter, Brea, CA, USA) according to the instruction of the Annexin V-FITC Apoptosis detection kit (Nanjing KeyGen Biotech Co., Ltd., Nanjing, China).

Total RNA extraction and quantitative reverse transcription$P C R$. Neogenin mRNA level was detected by the RT-PCR method (25). Total RNA was extracted using standard methods $(26,27)$. Approximately $2 \mu \mathrm{g}$ of total RNA was reverse transcribed into first strand cDNA using random primers for qRT-PCR analysis. The primer pairs used for PCR are as follows: neogenin (24): forward, 5'-GGAAGGAGGGG AATGAGACC-3' and reverse, 5'-AATCACGGGTAGGGT AGGTA-3'; $\beta$-actin forward, 5'-TCCCTGGAGAAGAGCTA CGA-3' and reverse, 5'-AGGAAGGAAGGCTGGAAGAG-3'. All the primers were synthesized by Sangon Biotech Co., Ltd. (Shanghai, China). Quantitative RT-PCR was done using the iQ SYBR Green Supermix (Bio-Rad Laboratories, Hercules, CA, USA). Interpretation of the relative gene expression was calculated using the $2^{-\triangle \Delta C T}$ method (28). $\beta$-actin mRNA was used as an internal control.

Western blot analysis. We performed western blot analysis as previously described (29). The cells were homogenized and lysed with RIPA lysis buffer (Beyotime, Nantong, China). The protein concentration was measured using a BCA protein assay kit (Beyotime). Equal amounts of protein lysate (40 $\mu \mathrm{g}$ /lane) were separated on $12 \%$ SDS-PAGE gels and electrophoretically transferred to polyvinylidene fluoride (PVDF) membranes. Then, the cells were incubated with primary antibodies specific for neogenin, Smad1/5/8 and $\beta$-actin. The blots were rinsed in TBST, and further incubated in HRP-conjugated rabbit anti-mouse IgG or HRP-conjugated goat anti-rabbit IgG. Bound proteins were visualized using enhanced chemiluminescence (ECL) reagent (Boehringer Mannheim, Mannheim, Germany).

SiRNA transfection. Breast cancer MDA-MB-231 cells with the neogenin protein were transfected with neogenin siRNA or the control siRNA (siMock) using Lipofectamine 2000 (Invitrogen) following the manufacturer's instructions. The coding strand of human neogenin siRNA (16) was 5'-AGAU CUGGAGGUUUCACAUCUUUGG-3'. The siRNA oligonucleotides were obtained from Shanghai Sangon. Neogenin siRNA and siMock-transfected cells were used for further experiments. Neogenin mRNA and protein levels were determined by RT-PCR and western blotting $24 \mathrm{~h}$ after transduction.

Statistics analysis. All data were obtained from at least three independent experiments and are expressed as mean \pm SD. Statistical analysis was performed using SPSS 13.0 software (SPSS, Inc., Chicago, IL, USA). Data were analyzed using analysis of variance (ANOVA) and Student's t-test. $\mathrm{P}<0.05$ was considered to indicate a statistically significant result.

\section{Results}

Increased neogenin levels in breast cancer cell lines MDA-MB-231, MCF-7 and T47D cells transduced with pcDNA3.1-neogenin. As a result of the RT-PCR and western 

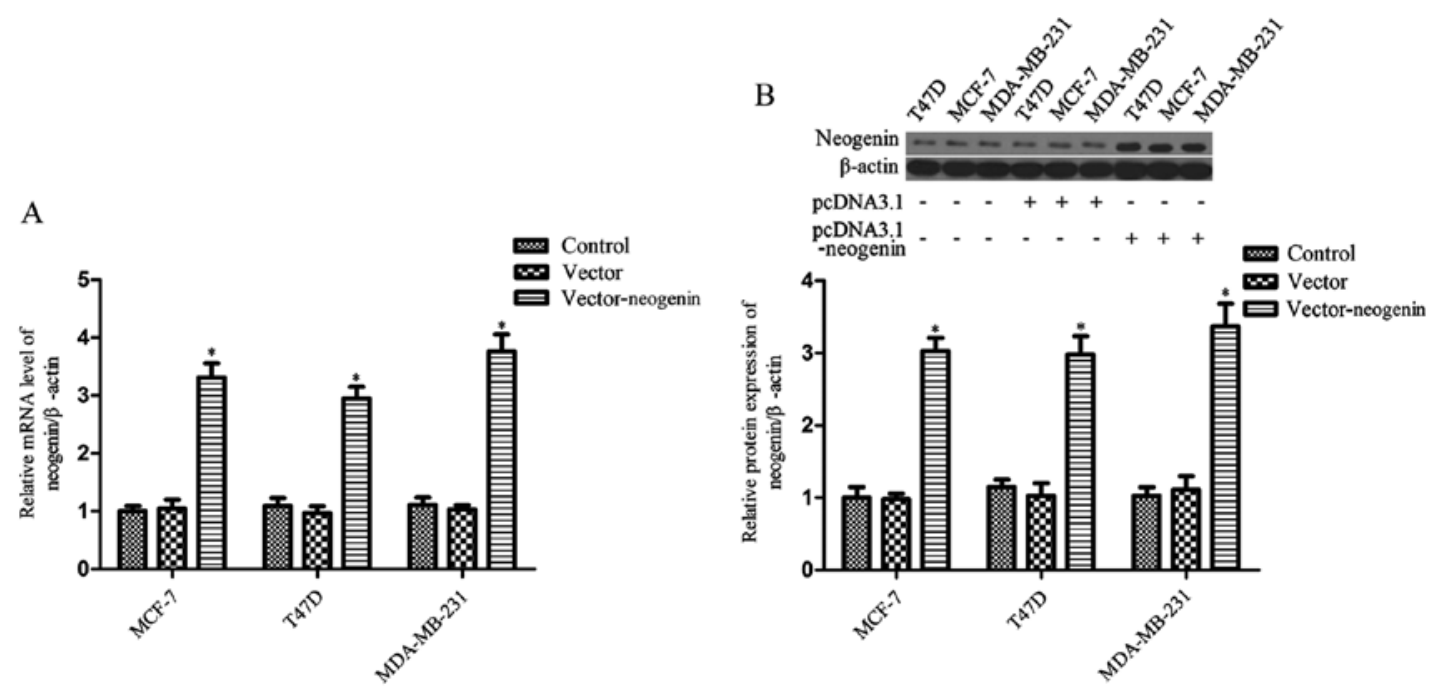

Figure 1. Analysis of neogenin mRNA and protein expression in human breast cancer cells after transduction. (A) Neogenin mRNA levels were measured by RT-PCR and normalized to $\beta$-actin. (B) The expression of neogenin protein was determined by western blot analysis. The relative levels of the neogenin normalized by $\beta$-actin values are shown in the graph. Values are presented as mean $\pm \mathrm{SD}$. "P<0.05 vs. control.

A

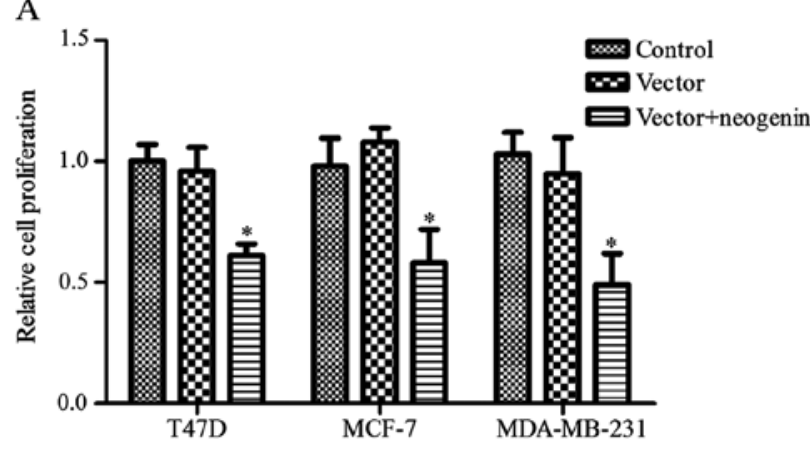

B

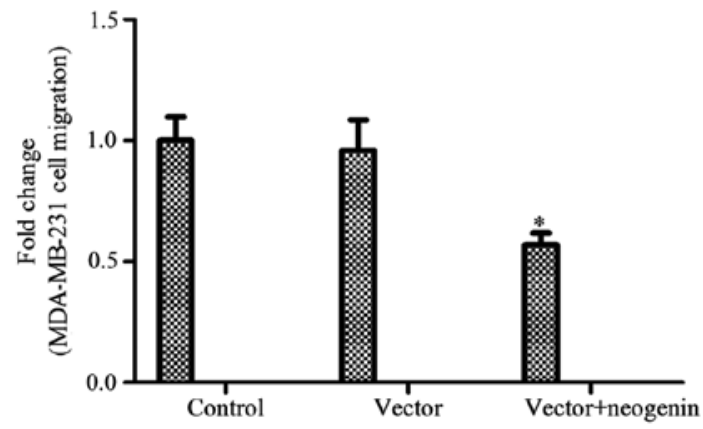

Figure 2. The effect of neogenin overexpression on breast cancer cell proliferation and migration. (A) Cell proliferation was assessed in three breast cancer cell lines (T47D, MCF-7 and MDA-MB-231) $48 \mathrm{~h}$ after transfection with pcDNA3.1-neogenin. (B) Cell migration of MDA-MB-231 breast cancer cells $48 \mathrm{~h}$ after transfection. Data are presented as mean $\pm \mathrm{SD}$. ${ }^{*} \mathrm{P}<0.05$ vs. control.

blot analysis of the three cell lines (MDA-MB-231, MCF-7 and T47D), the data show that neogenin mRNA and protein expression was weak (Fig. 1). Then, in order to further understand the role of neogenin in breast cancer, neogenin was overexpressed in the MDA-MB-231, MCF-7 and T47D cell lines by transfection. Cells were harvested after $48 \mathrm{~h}$ and neogenin expression was analyzed by RT-PCR and western blot analysis. The results show that neogenin mRNA and protein levels in the cells that were transduced with pcDNA3.1-neogenin for $48 \mathrm{~h}$ were much higher than in the control group (Fig. 1). The expression of neogenin was also upregulated in MDA-MB-231, MCF-7 and T47D cells transduced with pcDNA3.1-neogenin for 24,72 and $96 \mathrm{~h}$ (data not shown).

Effect of the overexpression of neogenin on breast cancer cell proliferation and migration. The neogenin overexpression vector was transfected into MDA-MB-231, MCF-7 and T47D cells, and then cell proliferation was measured by the MTT assay. As shown in Fig. 2A, the proliferation of MDA-MB-231, MCF-7 and T47D cells was greatly decreased with neogenin overexpression. Neogenin overexpression resulted in a 39, 42 and $51 \%$ decrease in the T47D, MCF-7 and MDA-MB-231 cell numbers, respectively. These results indicate that neogenin overexpression can inhibit the proliferation of all three breast cancer cell lines. Thus, we selected the breast cancer cell line MDA-MB-231 for further study. We also assessed the effects of neogenin overexpression on MDA-MB-231 cell migration. The results show that the migration of MDA-MB-231 cells was significantly decreased after neogenin overexpression (Fig. 2B).

Induction of apoptosis after neogenin overexpression in the breast cancer cell line MDA-MB-231. Reports have shown that neogenin overexpression can induce apoptosis in the human glioma cell line SHG-44 (20). Moreover, the present study indicates that neogenin overexpression inhibits breast cancer cell proliferation. Thus, we tested whether the change in the MDA-MB-231 cell numbers in our studies was also mediated by neogenin-induced apoptosis. Apoptosis was measured by flow cytometric analysis; the results are shown in Fig. 3. Flow cytometry showed that $33.9 \%$ of the cells that were transfected with neogenin underwent apoptosis compared to $5.6 \%$ in the 

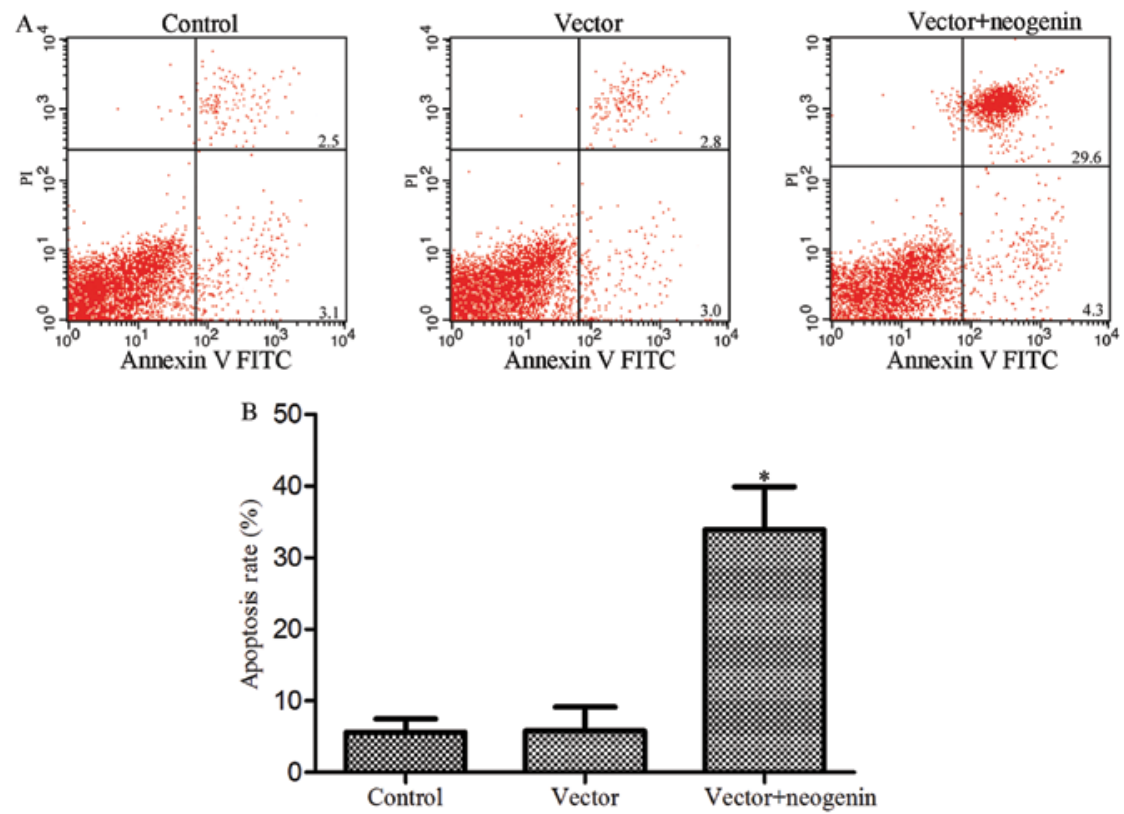

Figure 3. The effect of neogenin overexpression on breast cancer MDA-MB-231 cell apoptosis. (A) Flow cytometric analyses of MDA-MB-231 cell apoptosis. Cells were treated with pcDNA3.1-neogenin vector or blank vector for $48 \mathrm{~h}$. (B) Quantitative analysis of the apoptotic rate after transfection. Data are presented as mean $\pm \mathrm{SD}$. ${ }^{*} \mathrm{P}<0.05$ vs. control.
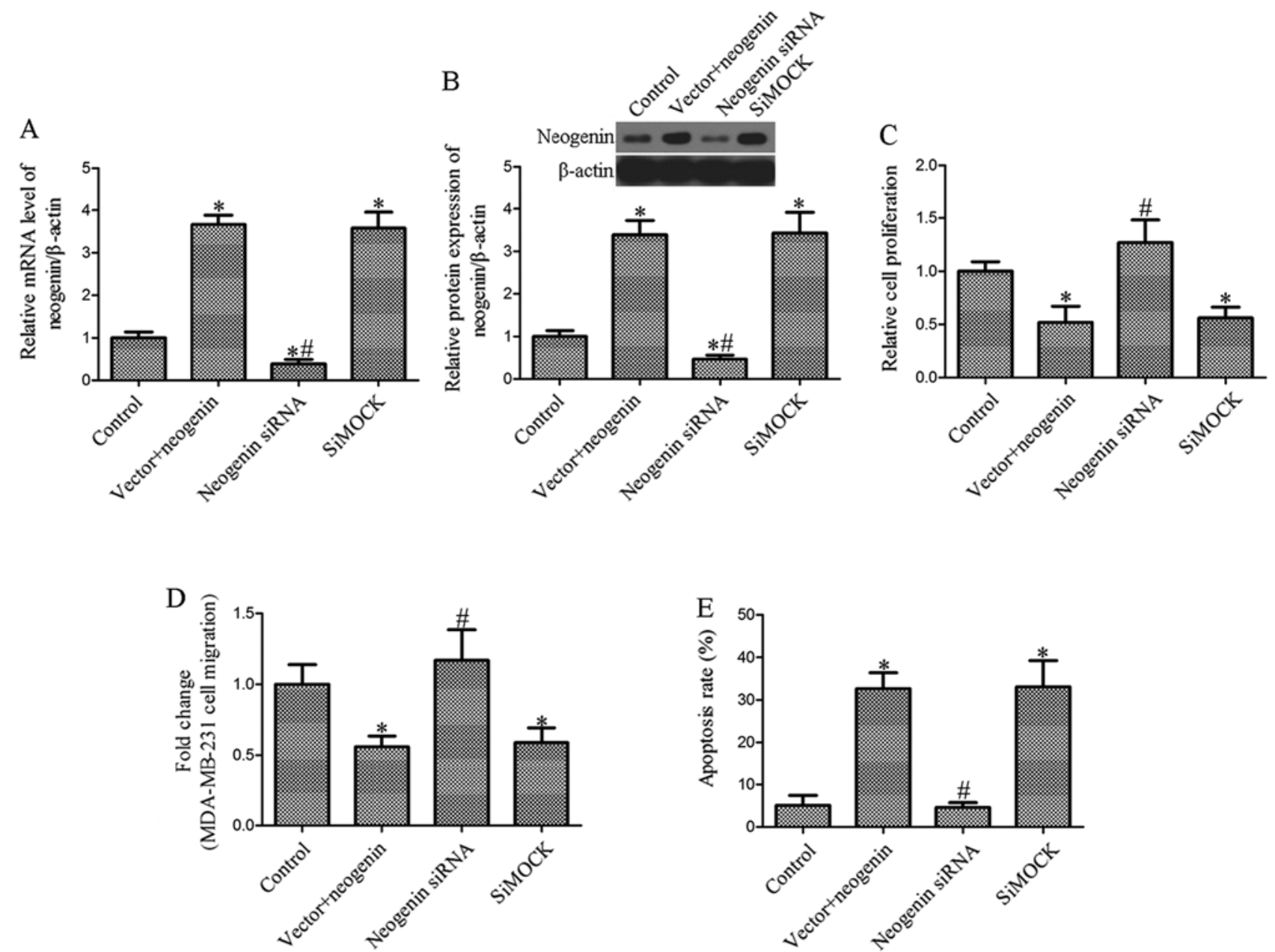

Figure 4. The effect of neogenin siRNA on the proliferation, migration and apoptosis of MDA-MB-231 transfected cells. (A) RT-PCR analyses of neogenin mRNA expression in neogenin siRNA and siMock treated cells. (B) Neogenin expression in neogenin siRNA and siMock treated cells by western blot analysis. The relative levels of neogenin normalized by $\beta$-actin values are shown in the graph. (C) The proliferation of MDA-MB-231 cells after neogenin siRNA and siMock treatment. (D) Cell migration of MDA-MB-231 breast cancer cells transfected by siRNA or siMock. (E) Cell apoptosis was detected by flow cytometry. Cells were treated with neogenin siRNA and siMock. Data are presented as mean $\pm \mathrm{SD}$. ${ }^{*} \mathrm{P}<0.05$ vs. control, ${ }^{\#} \mathrm{P}<0.05$ vs. neogenin overexpression group. 


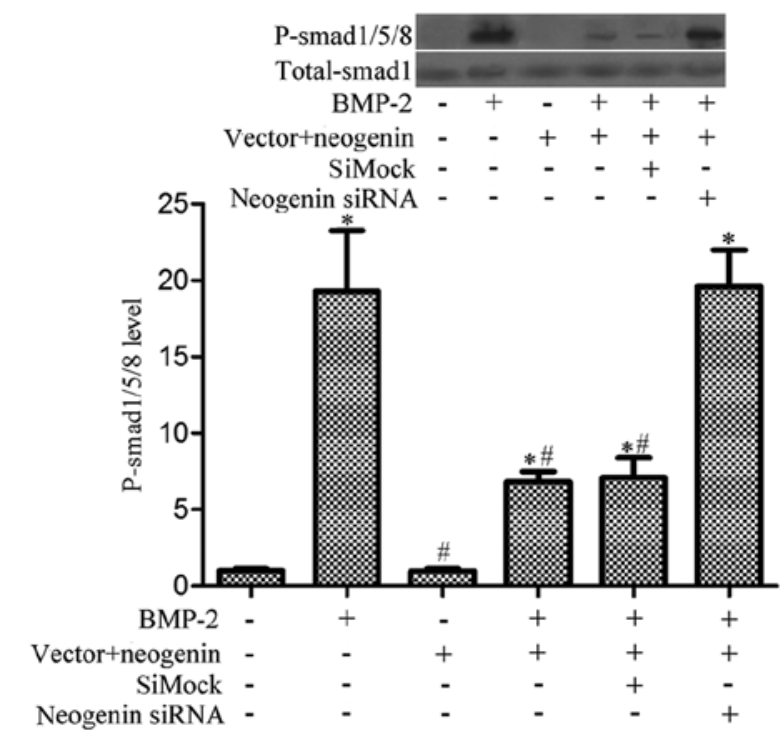

Figure 5. Effects of neogenin overexpression on the phosphorylation of Smad1/5/8. MDA-MB-231 cells were transfected with pcDNA3.1-neogenin, neogenin siRNA or control siRNA (siMock) and were treated with rhBMP-2 for $30 \mathrm{~min}$. The relative levels of P-Smad1/5/8 normalized by Smad 1 and were expressed as fold changes vs. Smad1. Data are presented as mean \pm SD ${ }^{\text {*P }}<0.05$ vs. control, ${ }^{\text {}} \mathrm{P}<0.05$ vs. BMP-2 treated group.

control group which were not transfected $(\mathrm{P}<0.05)$ and $5.8 \%$ in the vector group which were transfected with the empty vector $(\mathrm{P}<0.05)$. Similar to those reported in literature $(8)$, these results further suggest that neogenin may be a breast cancer suppressor by inducing apoptosis in breast cancer cells.

Effect of the ablation of neogenin on breast cancer cell proliferation, migration and apoptosis. To determine whether siRNAs inhibit the expression of neogenin, we first investigated the effects of siRNA on neogenin mRNA and protein expression in MDA-MB-231 cells transfected with neogenin. The level of neogenin was measured by RT-PCR and western blot analysis after transfection of siRNAs into the breast cancer cells. The results showed that the level of neogenin in breast cancer MDA-MB-231 cells transfected with neogenin siRNA was significantly decreased ( $\mathrm{P}<0.05$; Fig. 4A and $\mathrm{B}$ ). Then, we determined the effect of neogenin silencing on cell proliferation, migration and apoptosis. As shown in Fig. 4C, MDA-MB-231 cell growth was significantly increased in the neogenin siRNA-transfected group compared with the siMock-transfected group. Furthermore, we found that cell migration following the ablation of neogenin considerably increased the migration of MDA-MB-231 cells (Fig. 4D). Moreover, MDA-MB-231 cell apoptosis was also markedly decreased in the siRNA-transfected group (Fig. 4E). Our results showed that the effect of neogenin on proliferation, migration and apoptosis is associated with the overexpression of neogenin.

Overexpression of neogenin suppresses BMP-2-induced phosphorylation of Smad1/5/8 in breast cancer cells. Reports have suggested that BMP2 may act as a tumor suppressor by promoting apoptosis in many cell types, such as mature colonic epithelial and human colorectal cancer cells $(30,31)$. Moreover, some evidence indicates that BMP-2 can induce the phosphorylation of Smad1/5/8, which is prevented by neogenin (24). Furthermore, an important role for the Smad1/5/8 signaling pathway in migration was described in the bone marrow stromal cells (32). Therefore, we investigated if neogenininduced breast cancer cell migration and growth inhibition is related to the BMP-2-induced Smad1/5/8 signaling pathway. We treated MDA-MB-231 cells with rhBMP-2 $(0.1 \mathrm{mg} / \mathrm{ml})$ for $30 \mathrm{~min}$, and then analyzed the phosphorylation state of the receptor proteins Smad1/5/8 using an antibody that specifically recognizes phosphorylated $\mathrm{Smad} 1 / 5 / 8$. The results showed that phosphorylation of Smad1/5/8 was significantly decreased in neogenin overexpressing cells (Fig. 5). These data indicate that the Smad1/5/8 pathway is inhibited in neogenin-transfected cells.

\section{Discussion}

The main findings of the present study are as follows: i) neogenin is weakly expressed in breast cancer cells, and neogenin overexpression can inhibit breast cancer cell growth and migration; ii) neogenin overexpression can promote breast cancer MDA-MB-231 cell apoptosis; iii) neogenin silencing has no apparent effect on MDA-MB-231 cell growth, migration or apoptosis; and iv) neogenin overexpression is able to inhibit BMP-2-induced Smad1/5/8 phosphorylation. The results of the present study indicate that neogenin inhibits the progression of breast cancer in vitro, which can be explained by the growth and migration inhibition and pro-apoptosis effects of neogenin in breast cancer cells.

Breast cancer, a serious threat to the health of females, is a malignant tumor associated with the fastest growing female mortality rate, far surpassing lung cancer $(33,34)$. The incidents of breast cancer are increasing at an annual rate of 3\% in China (34). Treatment for breast cancer is far from satisfactory, and some evidence suggests that breast cancer is a genetic disease (35). The balance of oncogenes and tumor suppressor genes plays an important role in the regulation of cellular physiological processes and an abnormal balance may affect cell proliferation, differentiation, apoptosis and drug resistance $(36,37)$. Thus, it is possible that identifying novel targets may prevent or enhance the treatment of breast cancer (38). Evidence has suggested that neogenin is abnormally expressed in various cancers, including bladder cancer (8).

Although Meyerhardt and co-workers (39) suggested that neogenin is expressed in breast cancer cell lines and indicated that neogenin expression is unchanged in cancer, including bladder cancer, some studies have shown that neogenin expression is lower, in prostate (40), colon (41) and breast cancer (8). Our results are consistent with the existing data (8) which suggest that the expression of neogenin in breast cancer cells is inversely associated with the tumorigenicity of breast cancer. Considering the results of RT-PCR and western blot analysis on the three cell lines (T47D, MCF-7 and MDA-MB-231), the data show that neogenin was weakly expressed in these cells (Fig. 1). In order to study the effects of neogenin on the progression of breast cancer, we transfected the recombinant expression vector pcDNA3.1neogenin into the breast cancer cell lines T47D, MCF-7 and 
MDA-MB-231. The RT-PCR and western blot analysis results show that the expression of neogenin in the three cell lines was significantly upregulated (Fig. 1). Then, we demonstrated that a high level of neogenin was correlated with a decrease in cell proliferation and migration and an increase in cell apoptosis (Figs. 2 and 3). Neogenin siRNA was used to silence the expression of neogenin in neogenin-transfected cells. The results suggest that neogenin siRNA increased the cell number and migration and decreased apoptosis (Fig. 4). The data from the present study indicate that neogenin was able to inhibit the progression of breast cancer.

The functions of BMPs in cancer are situational and complex (42); our observations show that neogenin expression inhibits BMP-2-induced phosphorylation of Smad1/5/8 in breast cancer cells. Treatment of these cells with rh-BMP-2 led to an increase in the level of phosphorylation of Smad1/5/8; however, neogenin overexpression induced a marked decrease in the phosphorylation of Smad1/5/8. Moreover, the extent of the Smad1/5/8 phosphorylation in the siMock group was less than that in the neogenin siRNA group.

In summary, neogenin may play an important role in the progression of breast cancer. Upregulation of neogenin reduced breast cancer cell proliferation, inhibited migration and induced apoptosis. Collectively, neogenin can be considered a tumor suppressor in breast cancer. We demonstrated that neogenin expression may be inversely correlated to breast cancer. However, the specific mechanism of action of neogenin in breast cancer cells remains to be determined. Future studies on the role of neogenin in breast cancer will address these issues and enhance our knowledge of breast cancer.

\section{References}

1. Blanco MA and Kang Y: Signaling pathways in breast cancer metastasis - novel insights from functional genomics. Breast Cancer Res 13: 206, 2011.

2. Yang M, Chen J, Su F, Yu B, Su F, Lin L, Liu Y, Huang JD and Song E: Microvesicles secreted by macrophages shuttle invasionpotentiating microRNAs into breast cancer cells. Mol Cancer 10: 117, 2011.

3. Chaffer CL and Weinberg RA: A perspective on cancer cell metastasis. Science 331: 1559-1564, 2011.

4. Li L, Luo J, Wang B, Wang D, Xie X, Yuan L, Guo J, Xi S, Gao J, Lin X, et al: MicroRNA-124 targets flotillin-1 to regulate proliferation and migration in breast cancer. Mol Cancer 12: 163, 2013.

5. Burstein HJ, Griggs JJ, Prestrud AA and Temin S: American Society of Clinical Oncology clinical practice guideline update on adjuvant endocrine therapy for women with hormone receptor-positive breast cancer. J Oncol Pract 6: 243-246, 2010.

6. Dawood S, Merajver SD, Viens P, Vermeulen PB, Swain SM Buchholz TA, Dirix LY, Levine PH, Lucci A, Krishnamurthy S, et al: International expert panel on inflammatory breast cancer: Consensus statement for standardized diagnosis and treatment. Ann Oncol 22: 515-523, 2011.

7. Ashok M, Griffin P and Halpern M: Impact of clinical and nonclinical factors on the choice of HER2 test for breast cancer. Cancer Invest 28: 735-742, 2010.

8. Lee JE, Kim HJ, Bae JY, Kim SW, Park JS, Shin HJ, Han W, Kim SW, Kang KS and Noh DY: Neogenin expression may be inversely correlated to the tumorigenicity of human breast cancer. BMC Cancer 5: 154, 2005.

9. Fitzgerald DP, Bradford D and Cooper HM: Neogenin is expressed on neurogenic and gliogenic progenitors in the embryonic and adult central nervous system. Gene Expr Patterns 7: 784-792, 2007.
10. Yamashita T, Mueller BK and Hata K: Neogenin and repulsive guidance molecule signaling in the central nervous system. Curr Opin Neurobiol 17: 29-34, 2007.

11. Matsunaga E and Chedotal A: Repulsive guidance molecule/ neogenin: A novel ligand-receptor system playing multiple roles in neural development. Dev Growth Differ 46: 481-486, 2004.

12. Lejmi E, Leconte L, Pédron-Mazoyer S, Ropert S, Raoul W, Lavalette S, Bouras I, Feron JG, Maitre-Boube M, Assayag F, et al: Netrin-4 inhibits angiogenesis via binding to neogenin and recruitment of Unc5B. Proc Natl Acad Sci USA 105: 12491-12496, 2008.

13. Wilson NH and Key B: Neogenin: One receptor, many functions. Int J Biochem Cell Biol 39: 874-878, 2007.

14. Cole SJ, Bradford D and Cooper HM: Neogenin: A multifunctional receptor regulating diverse developmental processes. Int J Biochem Cell Biol 39: 1569-1575, 2007.

15. Wilson NH and Key B: Neogenin interacts with RGMa and netrin-1 to guide axons within the embryonic vertebrate forebrain. Dev Biol 296: 485-498, 2006.

16. Kim SJ, Wang YG, Lee HW, Kang HG, La SH, Choi IJ, Irimura T, Ro JY, Bresalier RS and Chun KH: Up-regulation of neogenin-1 increases cell proliferation and motility in gastric cancer. Oncotarget 5: 3386-3398, 2014.

17. Link BC, Reichelt U, Schreiber M, Kaifi JT, Wachowiak R, Bogoevski D, Bubenheim M, Cataldegirmen G, Gawad KA, Issa R, et al: Prognostic implications of netrin-1 expression and its receptors in patients with adenocarcinoma of the pancreas. Ann Surg Oncol 14: 2591-2599, 2007

18. Song S, Mazurek N, Liu C, Sun Y, Ding QQ, Liu K, Hung MC and Bresalier RS: Galectin-3 mediates nuclear beta-catenin accumulation and Wnt signaling in human colon cancer cells by regulation of glycogen synthase kinase-3beta activity. Cancer Res 69: 1343-1349, 2009.

19. Hu YC, Lam KY, Law S, Wong J and Srivastava G: Identification of differentially expressed genes in esophageal squamous cell carcinoma (ESCC) by cDNA expression array: Overexpression of Fra-1, Neogenin, Id-1, and CDC25B genes in ESCC. Clin Cancer Res 7: 2213-2221, 2001.

20. Wu X, Li Y, Wan X, Kayira TM, Cao R, Ju X, Zhu X and Zhao G: Down-regulation of neogenin accelerated glioma progression through promoter methylation and its overexpression in SHG-44 induced apoptosis. PLoS One 7: e38074, 2012.

21. Fujita Y, Taniguchi J, Uchikawa M, Endo M, Hata K, Kubo T, Mueller BK and Yamashita T: Neogenin regulates neuronal survival through DAP kinase. Cell Death Differ 15: 1593-1608, 2008.

22. Bolos V, Blanco M, Medina V, Aparicio G, Diaz-Prado S and Grande E: Notch signalling in cancer stem cells. Clin Transl Oncol 11: 11-19, 200.

23. Zardawi SJ, O'Toole SA, Sutherland RL and Musgrove EA: Dysregulation of Hedgehog, Wnt and Notch signalling pathways in breast cancer. Histol Histopathol 24: 385-398, 2009.

24. Hagihara M, Endo M, Hata K, Higuchi C, Takaoka K, Yoshikawa $\mathrm{H}$ and Yamashita T: Neogenin, a receptor for bone morphogenetic proteins. J Biol Chem 286: 5157-5165, 2011.

25. Yang ZQ, Liu G, Bollig-Fischer A, Haddad R, Tarca AL and Ethier SP: Methylation-associated silencing of SFRP1 with an 8p11-12 amplification inhibits canonical and non-canonical WNT pathways in breast cancers. Int J Cancer 125: 1613-1621, 2009.

26. Yang ZQ, Streicher KL, Ray ME, Abrams J and Ethier SP: Multiple interacting oncogenes on the 8p11-p12 amplicon in human breast cancer. Cancer Res 66: 11632-11643, 2006.

27. Yang ZQ, Imoto I, Fukuda Y, Pimkhaokham A, Shimada Y, Imamura $\mathrm{M}$, Sugano $\mathrm{S}$, Nakamura $\mathrm{Y}$ and Inazawa J: Identification of a novel gene, GASC1, within an amplicon at 9p23-24 frequently detected in esophageal cancer cell lines. Cancer Res 60: 4735-4739, 2000.

28. Livak KJ and Schmittgen TD: Analysis of relative gene expression data using real-time quantitative PCR and the 2(-Delta Delta C(T)) method. Methods 25: 402-408, 2001.

29. Feng X, Wu Z, Wu Y, Hankey W, Prior TW, Li L, Ganju RK, Shen $\mathrm{R}$ and Zou $\mathrm{X}$ : Cdc25A regulates matrix metalloprotease 1 through Foxo1 and mediates metastasis of breast cancer cells. Mol Cell Biol 31: 3457-3471, 2011.

30. Zhang Y, Chen X, Qiao M, Zhang BQ, Wang N, Zhang Z, Liao Z, Zeng L, Deng Y, Deng F, et al: Bone morphogenetic protein 2 inhibits the proliferation and growth of human colorectal cancer cells. Oncol Rep 32: 1013-1020, 2014. 
31. Hardwick JC, van den Brink GR, Bleuming SA, Ballester I, van den Brande JM, Keller JJ, Offerhaus GJ, van Deventer SJ and Peppelenbosch MP: Bone morphogenetic protein 2 is expressed by, and acts upon, mature epithelial cells in the colon. Gastroenterology 126: 111-121, 2004

32. $\mathrm{Hu} \mathrm{Y,} \mathrm{Du} \mathrm{Y,} \mathrm{Jiang} \mathrm{H}$ and Jiang GS: Cerium promotes bone marrow stromal cells migration and osteogenic differentiation via Smad1/5/8 signaling pathway. Int J Clin Exp Pathol 7: 5369-5378, 2014.

33. Engebraaten O, Vollan HK and Borresen-Dale AL: Triplenegative breast cancer and the need for new therapeutic targets. Am J Pathol 183: 1064-1074, 2013.

34. Li N, Zheng RS, Zhang SW, Zou XN, Zeng HM, Dai Z and Chen WQ: Analysis and prediction of breast cancer incidence trend in China. Zhonghua Yu Fang Yi Xue Za Zhi 46: 703-707, 2012 (In Chinese).

35. Yang S and Han H: Effect of cycloxygenase-2 silencing on the malignant biological behavior of MCF-7 breast cancer cells Oncol Lett 8: 1628-1634, 2014.

36. Veeck J, Noetzel E, Bektas N, Jost E, Hartmann A, Knüchel R and Dahl E: Promoter hypermethylation of the SFRP2 gene is a high-frequent alteration and tumor-specific epigenetic marker in human breast cancer. Mol Cancer 7: 83, 2008.
37. Zhang $X$ and Munster PN: New protein kinase inhibitors in breast cancer: afatinib and neratinib. Expert Opin Pharmacother 15: 1277-1288, 2014

38. De Los Santos JF, Cantor A, Amos KD, Forero A, Golshan M, Horton JK, Hudis CA, Hylton NM, McGuire K, Meric-Bernstam F, et al: Magnetic resonance imaging as a predictor of pathologic response in patients treated with neoadjuvant systemic treatment for operable breast cancer. Translational Breast Cancer Research Consortium trial 017. Cancer 119: 1776-1783, 2013.

39. Meyerhardt JA, Look AT, Bigner SH and Fearon ER: Identification and characterization of neogenin, a DCC-related gene. Oncogene 14: 1129-1136, 1997.

40. Latil A, Chêne L, Cochant-Priollet B, Mangin P, Fournier G, Berthon $\mathrm{P}$ and Cussenot O: Quantification of expression of netrins, slits and their receptors in human prostate tumors. Int J Cancer 103: 306-315, 2003.

41. Li VS, Yuen ST, Chan TL, Yan HH, Law WL, Yeung BH, Chan AS, Tsui WY, So S, Chen X, et al: Frequent inactivation of axon guidance molecule RGMA in human colon cancer through genetic and epigenetic mechanisms. Gastroenterology 137: 176-187, 2009.

42. Ye L, Lewis-Russell JM, Kyanaston HG and Jiang WG: Bone morphogenetic proteins and their receptor signaling in prostate cancer. Histol Histopathol 22: 1129-1147, 2007. 